\title{
Genotype-phenotype relationship in Japanese patients with congenital central hypoventilation syndrome
}

\author{
Tomoyuki Shimokaze ${ }^{1}$, Ayako Sasaki ${ }^{1}$, Toru Meguro ${ }^{1}$, Hisaya Hasegawa ${ }^{2}$, Yuka Hiraku ${ }^{3}$, Tetsushi Yoshikawa ${ }^{4}$, \\ Yumiko Kishikawa ${ }^{1}$ and Kiyoshi Hayasaka ${ }^{1,5}$
}

Examine the genotype-phenotype relationship in Japanese congenital central hypoventilation syndrome (CCHS) patients and estimate the incidence of CCHS in Japan. Subjects were 92 Japanese patients with PHOX2B mutations; 19 cases carried 25 polyalanine repeat expansion mutations (PARMs); 67 cases carried 26 or more PARMs; and 6 had non-PARMs (NPARMs). We collected clinical data in all patients and estimated the development or intelligent quotients only in the patients carrying 25 PARM. The estimated incidence of CCHS was greater than one case per 148000 births. Polyhydramnios was observed in three cases. Twelve infants exhibited depressed respiration at birth. In 19 cases carrying 25 PARM, the male-to-female ratio was $\sim$, no cases had Hirschsprung disease; 7 cases (37\%) developed hypoventilation after the neonatal period, and 8 cases $(42 \%)$ had mental retardation. In other $\mathbf{7 3}$ cases carrying $\mathbf{2 6}$ or more PARMs or NPARMs, male-to-female ratio was equal; patients frequently complicated with Hirschsprung disease and constipation, and all patients presented with hypoventilation in the neonatal period. Clinical symptoms were severe in most patients carrying long PARMs and NPARMs. In 25 PARM, additional genetic and/or epigenetic factors were required for CCHS development and male sex is likely a predisposing factor. The patients carrying 25 PARM frequently had mental retardation likely because they were not able to receive appropriate ventilation support following a definitive diagnosis owing to subtle and or irregular hypoventilation. Molecular diagnosis provides a definitive diagnosis and enables to receive appropriate ventilator support.

Journal of Human Genetics (2015) 60, 473-477; doi:10.1038/jhg.2015.65; published online 11 June 2015

\section{INTRODUCTION}

Congenital central hypoventilation syndrome (CCHS; OMIM209880) is a disorder that is characterized by a failure of the automatic control of breathing. Hypoventilation develops mainly during sleep, but can also be present during both wakefulness and sleep in severe cases. ${ }^{1,2}$ CCHS is a neurocristopathies (a failure of the migration or differentiation of neural crest-derived precursor cells) and is frequently accompanied by Hirschsprung disease, neuroblastoma and dysregulation of the autonomic nervous system. ${ }^{2-13}$ A report from France described an estimated incidence of CCHS of one per 200000 live births. ${ }^{14}$

CCHS is caused by a mutation in $P H O X 2 B$, which is essential for the development of the respiratory center and for the differentiation and induction of the autonomic nervous system. ${ }^{15-18}$ The PHOX2B gene is mapped on chromosome $4 \mathrm{p} 12$ and encodes a highly conserved homeobox transcription factor of 314 amino acids with two short and stable polyalanine repeats of 9 and 20 residues. ${ }^{19}$ Over $90 \%$ of patients with CCHS are heterozygous for polyalanine repeat expansion mutations (PARMs) in $\mathrm{PHOX} 2 \mathrm{~B}$ that can range from 24 to 33 alanines, and remaining $10 \%$ of patients have heterozygous non-PARMs (NPARMs) that include missense, nonsense and frameshift mutations in $\mathrm{PHOX} 2 \mathrm{~B} \cdot{ }^{20}$ Approximately $25 \%$ of the PARMs is inherited from the parents with somatic mosaicism or constitutive mutation, and the rest of $\sim 75 \%$ is de novo during spermatogenesis. $^{21-23}$

Disease severity in the patients carrying PARMs increases with increasing expansion of the alanine repeats. ${ }^{20,24,25}$ The patients carrying long PARMs or most NPARMs present with severe phenotype in neonatal period. ${ }^{26}$ In contrast, the individuals carrying 25 PARM or 24 PARM exhibit hypoventilation during the neonatal period or after the neonatal period and occasionally have no symptoms. ${ }^{2,20}$

Our facilities have provided a molecular diagnostic service for the majority of CCHS patients in Japan. Herein, we report an estimate of the incidence of CCHS in Japan and an analysis of the genotypephenotype relationship.

\section{METHODS}

Subjects

We analyzed the genotype-phenotype relationship of a total of 92 CCHS patients (male-to-female ratio, 49:43) who were diagnosed in the past 12 years including 11 cases previously reported. ${ }^{16,27-29}$ The median gestational age (GA)

\footnotetext{
${ }^{1}$ Department of Pediatrics, Yamagata University School of Medicine, Yamagata, Japan; ${ }^{2}$ Division of Neonatal Intensive Care, Tokyo Women's Medical University Medical Center East, Tokyo, Japan; ${ }^{3}$ Department of Obstetrics and Gynecology, Gifu Municipal Hospital, Gifu, Japan; ${ }^{4}$ Departments of Pediatrics, Fujita Health University School of Medicine, Toyoake, Aichi, Japan and ${ }^{5}$ Department of Pediatrics, Miyukikai Hospital, Kaminoyama, Japan Correspondence: Professor K Hayasaka, Department of Pediatrics, Yamagata University School of Medicine, 2-2-2 lida-nishi, Yamagata 990-9585, Japan. E-mail: hayasaka@med.id.yamagata-u.ac.jp

Received 22 February 2015; revised 7 May 2015; accepted 12 May 2015; published online 11 June 2015
} 
Table 1 Overview of $P H O X 2 B$ coding sequence status and clinical features

\begin{tabular}{|c|c|c|c|c|c|c|c|c|c|}
\hline \multirow[b]{2}{*}{$\begin{array}{l}\text { PHOX2B } \\
\text { status }\end{array}$} & \multirow[b]{2}{*}{$\begin{array}{c}\text { Number of } \\
\text { cases }\end{array}$} & \multirow[b]{2}{*}{$\begin{array}{l}\text { Male: } \\
\text { female }\end{array}$} & \multicolumn{2}{|c|}{ Apgar score ${ }^{\mathrm{a}}$} & \multicolumn{2}{|c|}{ Age at presentation of $\mathrm{CH}$} & \multirow[b]{2}{*}{$\begin{array}{c}\text { Constipation without } \\
\text { HSCR }\end{array}$} & \multirow[b]{2}{*}{ HSCR } & \multirow[b]{2}{*}{$\begin{array}{c}\text { Ventilation support during } \\
\text { wakefulness }\end{array}$} \\
\hline & & & $1 \mathrm{~min}$ & $5 \min$ & $\begin{array}{c}\text { Neonatal } \\
\text { period }\end{array}$ & $\begin{array}{c}\text { After neonatal } \\
\text { period }\end{array}$ & & & \\
\hline 25 PARM & 19 & $14: 5$ & $9(8-9)$ & $10(9-10)$ & 12 & 7 & 0 & 1 & 0 \\
\hline 26 PARM & 25 & $12: 13$ & $7(5-8)$ & $8(7-9)$ & 25 & 0 & 2 & 7 & 1 \\
\hline 27 PARM & 31 & $16: 15$ & $8(6-9)$ & $9(9-10)$ & 31 & 0 & 10 & 13 & 1 \\
\hline$>30$ PARM & 11 & $5: 6$ & $6(6-7)$ & $8(7-9)$ & 11 & 0 & 3 & 7 & 0 \\
\hline NPARM & 6 & $2: 4$ & $8(6-9)$ & $9(6-10)$ & 6 & 0 & 4 & 4 & 4 \\
\hline
\end{tabular}

Abbreviations: $\mathrm{CH}$, central hypoventilation; HSCR: Hirschsprung disease; NPARM, non-PARM; PARM, polyalanine repeat expansion mutations.

a values are expressed as median (IQR). Differences in Apgar score among the five $P H O X 2 B$ groups were significant at 1 min $(P<0.01)$ and 5 min $(P<0.05)$, respectively.

was 39 weeks (interquartile ranges: IQR $38-40$ weeks, these data were available in 81 cases), and the median birth weight was $2857 \mathrm{~g}$ (IQR 2602-3104 g, these data were available in 78 cases). Six cases were born at preterm delivery; one case was delivered at 33 weeks and five cases were delivered at 35-36 weeks of GA. Six cases were born post-term at 42 weeks of GA. One infant was heavy for date, and nine infants were light for date (data from 73 cases).

This study was approved by the institutional review board of Yamagata University School of Medicine, and written informed consents were obtained from the parents of all infants. The diagnoses followed the standard of the statement of the American Thoracic Society on CCHS. ${ }^{26}$ We collected clinical data including information about complications when the blood samples were received. In the patients with 25 PARMs, the developmental quotients or intelligence quotients were assessed using Enjoji's analytical development test, ${ }^{30}$ the revised version of the Kyoto Scale of psychological development ( $K$-test), ${ }^{31}$ or the Wechsler Preschool and Primary Scale of Intelligence. ${ }^{32}$ The intelligence quotients were assessed with the Wechsler Intelligence Scale for Children-Third Edition. ${ }^{33}$ The frequency of CCHS from 2008 to 2013 years was estimated comparing to the numbers of births each year in Japan, which were reported by the Ministry of Health and Labor and Welfare of Japan.

\section{Molecular analysis}

We extracted genomic DNA from peripheral blood using a standard method. The entire coding region and intron-exon boundaries of $P H O X 2 B$ were sequenced after polymerase chain reaction amplification as described previously. ${ }^{16,18,27,34}$ The sequence reactions were analyzed on an ABI PRISM 3100 Genetic Analyzer (PE Applied Biosystems, Foster City, CA, USA) with the BigDye Terminator Cycle Sequencing Ready Reaction Kit (PE Applied Biosystems, Foster City, CA, USA). ${ }^{16,34}$

\section{Statistics \\ Clinical data are expressed as median and IQR or range. The Pearson $\chi^{2}$-test was used to compare the proportions of male infants in the patients carrying 25 PARM and the patients carrying other genotypes. Differences between the two groups were compared with the Mann-Whitney $U$-test. The Kruskal-Wallis test was used for comparison of more than two groups. Spearman's correlation coefficients were used to identify the relationships within and between the different outcome measures. A $P$-value of $<0.05$ was considered to be statistically significant. The statistical analyses were performed using SPSS software, version 22 (IBM, Armonk, NY, USA).}

\section{RESULTS}

A total of 92 (including with two pairs of siblings) CCHS patients were studied. Molecular analyses of the $P H O X 2 B$ gene revealed that 86 cases had PARMs and six cases had six different NPARMs including the previously reported c.590delG and c.866InsG mutations ${ }^{16,26}$ and the novel c.609_616del8, c.678_693dup16, c.733_762dup30 and c.941_945del5 mutations (Table 1). The patient carrying 24 PARM was not found probably owing to low gene frequency and/or low penetrance.
The minimum estimated incidence of CCHS in Japan was one per 148000 births on average for the years of 2008-2013 (range 1 per 119 000-206 000 births).

Polyhydramnios was observed in three cases (25 PARM, 26 PARM and c.678_693dup16). The median Apgar score at one min was 8.0 (IQR 6.0-9.0, data were available in 69 cases) and at 5 min the median was 9.0 (IQR 7.5-9.5, data were available in 63 cases). Twelve infants (three with 25 PARM, five with 26 PARM, two with 27 PARM, one with 32 PARM and one with NPARM) were found to be depressed at birth (defined by an Apgar score below 4 at $1 \mathrm{~min}$ and/or 6 at $5 \mathrm{~min}$ ). The correlation coefficients $(r)$ between the alanine repeat expansions and the Apgar score were $-0.32(P<0.01)$ at $1 \mathrm{~min}$, and -0.10 $(P=0.44)$ at $5 \mathrm{~min}$, respectively.

Among the patients with 25 PARM, the male:female ratio was 14:5; i.e., approximately threefold more males than females were affected (Table 1). In contrast, there were no gender differences in the patients with the other genotypes; i.e., those with 26 or more PARMs and those with NPARMs. There was a significant difference in male dominance between the patients with 25 PARM and the patients with the other genotypes $(P=0.045)$.

Among the patients with 25 PARM, 12 of 19 patients (63\%) developed hypoventilation during the neonatal period, and the other seven cases (37\%) exhibited hypoventilation in the infantile period or childhood (Table 2). Four cases (the data for one case were not available) were diagnosed as CCHS in the neonatal period, and the median age of diagnosis was 4 months (IQR 1-33 months). No cases with 25 PARM had Hirschsprung disease.

All 73 cases carrying 26 or more PARMs or NPARMs exhibited apparent hypoventilation during the neonatal period. Ventilation support was required even during wakefulness in six cases carrying 26 PARM, 27 PARM and NPARMs except for the c.590delG mutation. Thirty-three of the 69 cases (the data for four cases were not available) were diagnosed as CCHS during the neonatal period, and the median age of diagnosis was one month (IQR $0-3$ months). There was a significant difference in the age of diagnosis between the patients with 25 PARM and the other genotypes $(P<0.01)$. There was a correlation between the length of the alanine repeats and the incidence of Hirschsprung disease $(r=0.327, P<0.01)$ or the rate of complication of constipation without Hirschsprung disease $(r=0.370, P<0.001)$. The patients with NPARMs except for the c.590delG mutation had Hirschsprung disease (Table 1). ${ }^{27}$

The median age of diagnosis of the patients with 25 PARM was 4 months, which was greater than that of the patients with other mutations. We were impressed that many patients carrying 25 PARM were mentally retarded and developmental quotients or intelligence quotients scores were assessed in the patients carrying 25 PARM as 
Table 2 Clinical features of the cases with 25 polyalanine repeat expansion mutations

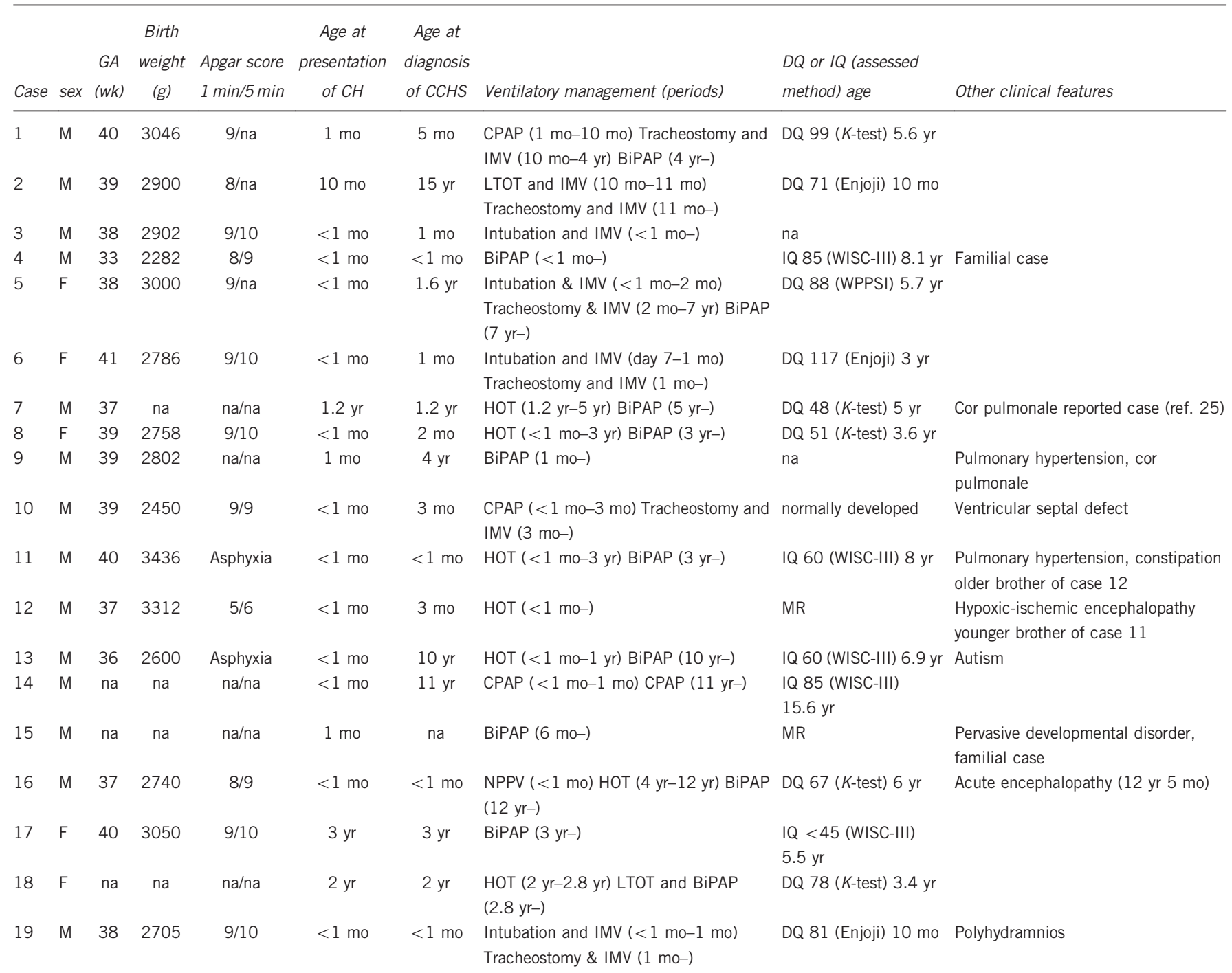

Abbreviations: BiPAP, biphasic positive airway pressure; CPAP, continuous positive airway pressure; $\mathrm{CH}$, central hypoventilation; DQ, developmental quotient; Enjoji, Enjoji's analytical development test; GA, gestational age; HOT, home oxygen therapy; IMV, intermittent mandatory ventilation; IQ, intelligence quotient; $K$-test, the revised version of Kyoto Scale of psychological development; LTOT, long-term oxygen therapy; mo, month; MR, apparently mentally retarded but not scored by a standardized method; na, not available; NPPV, noninvasive positive pressure ventilation; WPPPSI, Wechsler Preschool and Primary Scale of Intelligence; WISC-III, Wechsler Intelligence Scale for Children-third edition; yr, year.

shown in Table 2, and 8 of the 19 cases (42\%) with 25 PARM were complicated by mental retardation (Table 2 ).

\section{DISCUSSION}

We detected 92 cases of $P H O X 2 B$ mutation-confirmed CCHS in Japan, estimated an incidence of $>1$ per 148000 births. And in the cases carrying 25 PARM we found a male dominance and the frequent complication of mental retardation

There had not been previous epidemiological data about CCHS in Japan. Our 6-year analysis estimated the incidence of CCHS in Japan to be $>1$ case per 148000 births, which was not significantly different from the estimated incidence of 1 case per 200000 births that has been previously reported in France. ${ }^{14}$ The cases that underwent genetic diagnosis seemed to represent nearly all of the patients in Japan because our facilities provide a unique genetic screening service for the molecular diagnosis of CCHS in Japan. However, this study was not based on clinical phenotype surveillance, and the cases that were only diagnosed clinically and those that were diagnosed molecularly in other countries were not included.

Notably, the number of male patients with 25 PARM was three times greater than the number of female patients with 25 PARM. The individuals carrying 25 PARM exhibited hypoventilation during the neonatal period or after the neonatal period and occasionally had no symptoms. In contrast, the patients with 26 or more PARMs did not show any sex differences and exhibited hypoventilation during the neonatal period. PARMs in $P H O X 2 B$ have been shown to impair transcriptional function, and transcriptional impairment increases with expansion length for polyalanine repeat. ${ }^{18}$ The 26 or more PARMs definitely impair the function of PHOX2B, have complete penetrance, and cause CCHS in both male and female infants. However, 25 PARM exhibited incomplete penetrance, which suggests that other genetic and/or epigenetic factors are possibly involved in the clinical onset of CCHS. One study reported that two women carrying 25 and 26 PARMs experienced improvements in hypoventilation 
following the use of contraceptive pills that contained desogestrel, which is a potent progestin. ${ }^{35}$ Progesterone derivatives are known to exert stimulatory effects on the respiration. ${ }^{36}$ Prepubertal females have higher estrogen and lower testosterone and $17 \mathrm{OH}$-progesterone levels than the prepubertal males. ${ }^{37-39}$ In addition, in immature rats, there are gender differences in the estrogen levels in the cortex and hypothalamus despite the equivalent blood estrogen levels. ${ }^{40}$ The possible mechanisms by which sex hormones might modulate breathing include direct or indirect effects on regulatory gene expression in respiratory neurons. Our study was small and thus cannot completely exclude sampling bias. The male dominance among patients with 25 PARM should be confirmed in more patients.

Eight cases with 25 PARM (42\%) displayed apparent mental retardation. Before the disease-causing gene was identified, intellectual and cognitive deficits were commonly reported in CCHS patients. ${ }^{41,42}$ Zeiko et al. ${ }^{43}$ assessed the intellectual and cognitive abilities of 20 patients with $\mathrm{PHOX} 2 \mathrm{~B}$ mutation who had been diagnosed at neonates and placed under respiratory control. These authors found that the general Intelligence Index (full-scale intelligence quotients) of these patients was $84.9 \pm 23.6$ (mean \pm s.d.) and that the PHOX2B genotype and disease severity indicators were unrelated to neurocognitive indices. ${ }^{43}$ Our seven cases were observed to exhibit central hypoventilation in the infantile period or childhood. However, developmental or intellectual deficits were not always associated with the age of onset or the age at diagnosis of CCHS as shown in Table 2. Five of the eight patients with intelligence deficits received home oxygen therapy. Patients with 25 PARM might be under-diagnosed owing to subtle and or irregular hypoventilation and thus not receive appropriate ventilatory support, which might frequently cause the complication of mental retardation due to hypoxic encephalopathy. Early and definitive diagnoses based on $P H O X 2 B$ analysis are convenient and useful for preventing neurological sequelae.

In addition, we observed depression at birth in 12 cases and polyhydramnios in 3 cases. The number of infants who exhibited low Apgar scores at $1 \mathrm{~min}$ was correlated with an increased number of polyalanine repeats, suggesting one of the symptoms of CCHS. The pregnancies of three cases $(3.3 \%)$ were complicated by polyhydramnios. Polyhydramnios accompanied by a Chiari I malformation has been reported in one CCHS patient. ${ }^{44}$ Faure et al. ${ }^{4}$ observed esophageal dysmotility in seven cases via esophageal manometry and speculated that the underlying mechanism might be dysfunctions of the central structures that control swallowing. The complication of polyhydramnios might be derived from a dysfunction of swallowing control that is similar to that observed in congenital myotonic dystrophy.

In summary, we studied 92 Japanese patients with CCHS, estimated an incidence of CCHS and found a male dominance and the frequent complication of mental retardation in the cases carrying 25 PARM. Male sex is likely a predisposing factor for the patients carrying 25 PARM, who frequently had mental retardation likely because they presented subtle and or irregular hypoventilation and could not receive appropriate ventilation support following a definitive diagnosis.

\section{CONFLICT OF INTEREST}

The authors declare no conflict of interest.

\section{ACKNOWLEDGEMENTS}

This research was supported in part by a Grant-in-Aid for Scientific Research (C) from the Ministry of Education, Science, Culture and Sports of Japan and by a Grant from the Ministry of Health, Labour and Welfare in Japan. We appreciate Dr H. Kawawaki, Dr K. Maruyama, Dr T. Fujiwaki,
Dr H. Sakamoto, Dr H. Ushiku, Dr R. Kakinuma, Dr T. Kimura, Dr R. Suzuki, Dr N. Fueki, Dr R. Nogami, Dr M. Kai, Dr Y. Isobe, Dr M. Kajita,

Dr M. Yoshii, Dr T. Yamauchi, Dr K. Tanda, and Dr M. Kishida for providing patient information.

1 Mellins, R. B., Balfour, H. H. Jr., Turino, G. M. \& Winters, R. W. Failure of automatic control of ventilation (Ondine's curse). Report of an infant born with this syndrome and review of the literature. Medicine (Baltimore) 49, 487-504 (1970).

2 Weese-Mayer, D. E., Shannon, D. C., Keens, T. G. \& Silvestri, J. M. Idiopathic congenital central hypoventilation syndrome: diagnosis and management. Am. J. Respir. Crit. Care Med. 160, 368-373 (1999).

3 Goldberg, D. S. \& Ludwig, I. H. Congenital central hypoventilation syndrome: ocular findings in 37 children. J. Pediatr. Ophthalmol. Strabismus 33, 175-180 (1996).

4 Faure, C., Viarme, F., Cargill, G., Navarro, J, Gaultier, C. \& Trang, H. Abnormal esophageal motility in children with congenital central hypoventilation syndrome. Gastroenterology 122, 1258-1263 (2002).

5 Silvestri, J. M., Weese-Mayer, D. E. \& Flanagan, E. A. Congenital central hypoventilation syndrome: cardiorespiratory responses to moderate exercise, simulating daily activity. Pediatr. Pulmonol. 20, 89-93 (1995).

6 Paton, J. Y., Swaminathan, S., Sargent, C. W., Hawksworth, A. \& Keens, T. G. Ventilatory response to exercise in children with congenital central hypoventilation syndrome. Am. Rev. Respir. Dis. 147, 1185-1191 (1993).

7 Shea, S. A., Andres, L. P., Shannon, D. C., Guz, A. \& Banzett, R. B. Respiratory sensations in subjects who lack a ventilatory response to CO2. Respir. Physiol. 93, 203-219 (1993).

8 Spengler, C. M., Banzett, R. B., Systrom, D. M., Shannon, D. C. \& Shea, S. A Respiratory sensations during heavy exercise in subjects without respiratory chemosensitivity. Respir. Physiol. 114, 65-74 (1998).

9 Trang, H., Girard, A., Laude, D. \& Elghozi, J. L. Short-term blood pressure and heart rate variability in congenital central hypoventilation syndrome (Ondine's curse). Clin. Sci. (Lond) 108, 225-230 (2005).

10 O'Brien, L. M., Holbrook, C. R., Vanderlaan, M., Amiel, J. \& Gozal, D. Autonomic function in children with congenital central hypoventilation syndrome and their families. Chest 128, 2478-2484 (2005).

11 Gronli, J. O., Santucci, B. A., Leurgans, S. E., Berry-Kravis, E. M. \& Weese-Mayer, D. E. Congenital central hypoventilation syndrome: PHOX2B genotype determines risk for sudden death. Pediatr. Pulmonol. 43, 77-86 (2008).

12 Silvestri, J. M., Hanna, B. D., Volgman, A. S., Jones, P. J., Barnes, S. D. \& Weese-Mayer, D. E. Cardiac rhythm disturbances among children with idiopathic congenital central hypoventilation syndrome. Pediatr. Pulmonol. 29, 351-358 (2000).

13 Woo, M. S., Woo, M. A., Gozal, D., Jansen, M. T., Keens, T. G. \& Harper, R. M. Heart rate variability in congenital central hypoventilation syndrome. Pediatr. Res. 31, 291-296 (1992).

14 Trang, H., Dehan, M., Beaufils, F., Zaccaria, I., Amiel, J. \& Gaultier, C. The French Congenital Central Hypoventilation Syndrome Registry: general data, phenotype, and genotype. Chest 127, 72-79 (2005).

15 Amiel, J., Laudier, B., Attie-Bitach, T., Trang, H., de Pontual, L., Gener, B et al. Polyalanine expansion and frameshift mutations of the paired-like homeobox gene PHOX2B in congenital central hypoventilation syndrome. Nat. Genet. 33 459-461 (2003)

16 Sasaki, A., Kanai, M., Kijima, K., Akaba, K., Hashimoto, M., Hasegawa, H. et al. Molecular analysis of congenital central hypoventilation syndrome. Hum. Genet. 114, 22-26 (2003).

17 Weese-Mayer, D. E., Berry-Kravis, E. M., Zhou, L., Maher, B. S., Silvestri, J. M., Curran, M. E. et al. Idiopathic congenital central hypoventilation syndrome: analysis of genes pertinent to early autonomic nervous system embryologic development and identification of mutations in PHOX2b. Am. J. Med. Genet. A 123A 267-278 (2003)

18 Matera, I., Bachetti, T., Puppo, F., Di Duca, M., Morandi, F., Casiraghi, G. M. et al. PHOX2B mutations and polyalanine expansions correlate with the severity of the respiratory phenotype and associated symptoms in both congenital and late onset Central Hypoventilation syndrome. J. Med. Genet. 41, 373-380 (2004).

19 Yokoyama, M., Watanabe, H. \& Nakamura, M. Genomic structure and functional characterization of NBPhox (PMX2B), a homeodomain protein specific to catecholaminergic cells that is involved in second messenger-mediated transcriptional activation. Genomics 59, 40-50 (1999).

20 Weese-Mayer, D. E., Rand, C. M., Berry-Kravis, E. M., Jennings, L. J. Loghmanee, D. A., Patwari, P. P. et al. Congenital central hypoventilation syndrome from past to future: model for translational and transitional autonomic medicine. Pediatr. Pulmonol. 44, 521-535 (2009).

21 Arai, H., Otagiri, T., Sasaki, A., Hashimoto, T., Umetsu, K., Tokunaga, K. et al. De novo polyalanine expansion of $\mathrm{PHOX} 2 \mathrm{~B}$ in congenital central hypoventilation syndrome unequal sister chromatid exchange during paternal gametogenesis. J. Hum. Genet. 52, 921-925 (2007)

22 Bachetti, T., Parodi, S., Di Duca, M., Santamaria, G., Ravazzolo, R. \& Ceccherini, I. Low amounts of PHOX2B expanded alleles in asymptomatic parents suggest unsuspected recurrence risk in congenital central hypoventilation syndrome. J. Mol. Med. (Berl) 89, 505-513 (2011). 
23 Meguro, T., Yoshida, Y., Hayashi, M., Toyota, K., Otagiri, T., Mochizuki, N. et al. Inheritance of polyalanine expansion mutation of $P H O X 2 B$ in congenital central hypoventilation syndrome. J. Hum. Genet. 57, 335-337 (2012).

24 Trochet, D., O'Brien, L. M., Gozal, D., Trang, H., Nordenskjöld, A., Laudier, B. et al. $\mathrm{PHOX} 2 \mathrm{~B}$ genotype allows for prediction of tumor risk in congenital central hypoventilation syndrome. Am. J. Hum. Genet. 76, 421-426 (2005).

25 Berry-Kravis, E. M., Zhou, L., Rand, C. M. \& Weese-Mayer, D. E. Congenital central hypoventilation syndrome: PHOX2B mutations and phenotype. Am. J. Respir. Crit. Care Med. 174, 1139-1144 (2006).

26 Weese-Mayer, D. E., Berry-Kravis, E. M., Ceccherini, I., Keens, T. G., Loghmanee, D. A. \& Trang, H. An official ATS clinical policy statement: Congenital central hypoventilation syndrome: genetic basis, diagnosis, and management. Am. J. Respir. Crit. Care Med. 181, 626-644 (2010).

27 Amimoto, Y., Okada, K., Nakano, H., Sasaki, A., Hayasaka, K. \& Odajima, H. A case of congenital central hypoventilation syndrome with a novel mutation of the PHOX2B gene presenting as central sleep apnea. J. Clin. Sleep Med. 10, 327-329 (2014).

28 Horiuchi, H., Sasaki, A., Osawa, M., Kijima, K., Ino, Y., Matoba, R. et al. Sensitive detection of polyalanine expansions in $\mathrm{PHOX} 2 \mathrm{~B}$ by polymerase chain reaction using bisulfite-converted DNA. J. Mol. Diagn. 7, 638-640 (2005).

29 Fujiwaki, T., Hasegawa, H., Arai, H., Hayasaka, K. \& Ohta, S. Slowly progressive sleep apnea in late-onset central hypoventilation syndrome. Pediatr. Int. 54, 290-202 (2012)

30 Enjoji, M. Analytical Development Test of Infants, (Keio-Tsushin, Tokyo, Japan, 1962)

31 Brittain, M. The WPPSI: a Midlands study. Brit. J. Educ. Psychol. 39 14-17 (1969)

32 Koyama, T., Osada, H., Tsujii, H. \& Kurita, H. Utility of the Kyoto scale of psychological development in cognitive assessment of children with pervasive developmental disorders. Psychiatry Clin. Neurosci. 63, 241-243 (2009).

33 Wechsler, D. Wechsler Intelligence Scale for Children-Manual, 3rd edn (The Psychological Corporation, San Antonio, TX, 1991)
34 Trochet, D., de Pontual, L., Straus, C., Gozal, D., Trang, H., Landrieu, P. et al. PHOX2B germline and somatic mutations in late-onset central hypoventilation syndrome. Am. J. Respir. Crit. Care Med. 177, 906-911 (2008).

35 Straus, C., Trang, H., Becquemin, M. H., Touraine, P. \& Similowski, T. Chemosensitivity recovery in Ondine's curse syndrome under treatment with desogestrel. Respir. Physiol. Neurobiol. 171, 171-174 (2010).

36 Behan, M. \& Wenninger, J. M. Sex steroidal hormones and respiratory control. Respir. Physiol. Neurobiol. 164, 213-221 (2008).

37 Sulcova, J., Hill, M., Hampl, R. \& Starka, L. Age and sex related differences in serum levels of unconjugated dehydroepiandrosterone and its sulphate in normal subjects. J. Endocrinol. 154, 57-62 (1997).

38 Winter, J. S., Hughes, I. A., Reyes, F. I. \& Faiman, C. Pituitary-gonadal relations in infancy: 2. Patterns of serum gonadal steroid concentrations in man from birth to two years of age. J. Clin. Endocrinol. Metab. 42, 679-686 (1976).

39 Klein, K. O., Baron, J., Colli, M. J., McDonnell, D. P. \& Cutler, G. B. Jr. Estrogen levels in childhood determined by an ultrasensitive recombinant cell bioassay. J. Clin. Invest. 94, 2475-2480 (1994).

40 Amateau, S. K., Alt, J. J., Stamps, C. L. \& McCarthy, M. M. Brain estradiol content in newborn rats: sex differences, regional heterogeneity, and possible de novo synthesis by the female telencephalon. Endocrinology 145, 2906-2917 (2004).

41 Oren, J., Kelly, D. H. \& Shannon, D. C. Long-term follow-up of children with congenital central hypoventilation syndrome. Pediatrics 80, 375-380 (1987).

42 Marcus, C. L., Jansen, M. T., Poulsen, M. K., Keens, S. E., Nield, T. A. \& Lipsker, L. E. et al. Medical and psychosocial outcome of children with congenital central hypoventilation syndrome. J. Pediatr. 119, 888-895 (1991).

43 Zelko, F. A., Nelson, M. N., Leurgans, S. E., Berry-Kravis, E. M. \& Weese-Mayer, D. E. Congenital central hypoventilation syndrome: neurocognitive functioning in school age children. Pediatr. Pulmonol. 45, 92-98 (2010).

44 Bachetti, T., Robbiano, A., Parodi, S., Matera, I., Merello, E., Capra, V. et al. Brainstem anomalies in two patients affected by congenital central hypoventilation syndrome. Am. J. Respir. Crit. Care Med. 174, 706-709 (2006). 